\title{
Temporal Variation of Particulate Matter Concentrations within the Urban Area of Athens, Greece
}

\author{
Hina Najam ${ }^{1}$, Konstantinos P. Moustris ${ }^{2, *}$, Panagiotis T. Nastos ${ }^{3}$ \\ ${ }^{1}$ Mechanical Engineering Department, Abdullah Gül University, Barbaros mah, Ekilet bul, 38080 \\ Kocasinan/Kayseri, Turkey, hina.najam@agu.edu.tr \\ ${ }^{2}$ Laboratory of Fluid Mechanics, Mechanical Engineering Department, Piraeus University of Applied \\ Sciences, 250 Thivon and P. Ralli Str., GR-12244 Athens, Greece, kmoustris@puas.gr \\ ${ }^{3}$ Laboratory of Climatology and Atmospheric Environment, Faculty of Geology and Geoenvironment, \\ University of Athens, Panepistimiopolis Camp, GR-15784 Athens, Greece, nastos@geol.uoa.gr \\ *Corresponding Author: kmoustris@puas.gr
}

\begin{abstract}
The main objective of this work is to investigate the temporal variation of $\mathrm{PM}_{10}$ concentrations within the urban area of Athens during the years 2001-2015. For this purpose, the time series of the particulate matter with aerodynamic diameter less than $10 \mu \mathrm{m}$ $\left(\mathrm{PM}_{10}\right)$ is recorded for a 15-year period (2001-2015) in two different monitoring stations located in the urban area of Athens. The results show a totally different behavior of $\mathrm{PM}_{10}$ concentrations between the Athens city center and the suburban areas. It seems that in the city center the main sources of $\mathrm{PM}_{10}$ are traffic and heating systems especially during the cold period of the year. Furthermore, in the city center a significant seasonal variation was found with high concentrations during the cold period of the year and lower concentrations during the warm period of the year. Moreover, it was found that during the weekends, there is a decrease in $\mathrm{PM}_{10}$ concentrations probably due to the fact that majority of people do not use their vehicles. Finally, for both locations a significant temporal decreasing trend of the mean annual $\mathrm{PM}_{10}$ concentrations was found which indicates that during the last years, there have been improvements towards a better air quality.
\end{abstract}

\section{Keywords}

particulate matter; temporal variation; urban area of Athens; Greece

\section{Introduction}

Particulate matter with aerodynamic diameter less than $10 \mu \mathrm{m}\left(\mathrm{PM}_{10}\right)$ is a mixture of solid particles and liquid droplets. In general terms, particulate matter can be a mixture of combustion particles, organic matter, metals, sulphates, nitrates, sea salt, dust, etc. The sources of $\mathrm{PM}_{10}$ in the atmosphere are burning fuels, such as wood and coal (in home heating systems and industry) and petrol and diesel (from vehicles). There are also natural sources such as volcanoes, pollen, wild fires, dust, and sea salt. Furthermore, particulate matter can be formed in the air from reactions between gases or between gases and other particles.

Several epidemiological studies have shown a link between particulate air pollution and adverse health effects [1-6]. Ambient particles, among other environmental factors, are considered to have a strong impact on the air quality and are of great concern in healthrelated problems, especially the inhalable particulate matter [7-9]. PM10 can get deep into 
the lungs and may trigger asthma exacerbation [10-13]. The mechanism that is responsible for these health effects remains largely unknown. As the particles are made of partially inert carbon, which does not have bioactive properties, their pathogenic component has not been identified yet. Fine particles also contain biological components such as endotoxin, transition metals and gases such as polycyclic aromatic hydrocarbons. All these gases can cause inflammation when cultured with lung cells [14].

Like most European metropolitan cities, Athens suffers with the problem of air pollution. Concerning the greater Athens area (GAA), there are two major air pollutants, particulate matter and ozone. Many researchers have investigated the $\mathrm{PM}_{10}$ concentrations within the urban environment of the GAA. Progiou and Ziomas [15] developed a cost efficient comprehensive method in order to help decision makers to take the most appropriate measures towards particulates pollution abatement. The method was based on the estimation of source apportionment from the application of 3D meteorological and dispersion modeling and was validated with the use of 10 years (2002-2012) $\mathrm{PM}_{10}$ monitoring data, in Athens, Greece, as well as using $\mathrm{PM}_{10}$ emission data for the same area and time period. Paraskevopoulou et al. [16] in order to identify the sources of aerosols within the GAA collected a total of 1510 daily samples of fine (PM2.5) and coarse (PM102.5) aerosols at a suburban site (Penteli), during a five-year period (May 2008-April 2013) corresponding to the period before and during the Greek financial crisis. In addition, aerosol sampling was also conducted in parallel at an urban site (Thissio), during specific, short-term campaigns during all seasons of the year. In all these samples, mass and chemical composition measurements were performed, the latest only at the fine fraction. Benas et al. [17] developed multiple linear and higher order equations for the estimation of the $\mathrm{PM}_{10}$ spatial distribution over the broader area of Athens, Greece, based on satellite data. In situ $\mathrm{PM}_{10}$ measurements for the period 2007-2010 were used to calibrate the satellite observations. Remoundaki et al. [18] in their study reported results on $\mathrm{PM}_{10}$ monitored at an urban site of Athens, Greece at $14 \mathrm{~m}$ above ground level during an intense Sahara dust transport event. According to their results, sulfur and heavy metal concentrations were associated to local emissions as well as to very fine particles $<1 \mu \mathrm{m}$. Grivas et al. [19] in their study analyzed $\mathrm{PM}_{10}$ concentrations that have been collected by the Greek air quality-monitoring network at 8 different locations over the GAA, for the period of 2001-2004. The primary objectives were to assess the degree of compliance with the European Union-legislated air quality standard for $\mathrm{PM}_{10}$ and also to provide an overall statistical examination of the factors controlling the seasonal and spatial variation of concentrations, over the wider urban agglomeration of Athens city.

In the present work, the temporal variation of $\mathrm{PM}_{10}$ concentrations within the urban GAA during the time period 2001-2015 is studied in order to provide a guide of $\mathrm{PM}_{10}$ variation during the day, the week, the month and the whole year.

\section{Results and Discussion}

For this specific work, mean daily $\mathrm{PM}_{10}$ concentrations from two different locations within the GAA were used, covering the time period 2001-2015. Initially, the mean annual $\mathrm{PM}_{10}$ concentrations for both ARI (city center) and THR (suburban area) were calculated. Figure 1 depicts the variation of mean annual $\mathrm{PM}_{10}$ concentrations for ARI station (a) and THR station (b). 


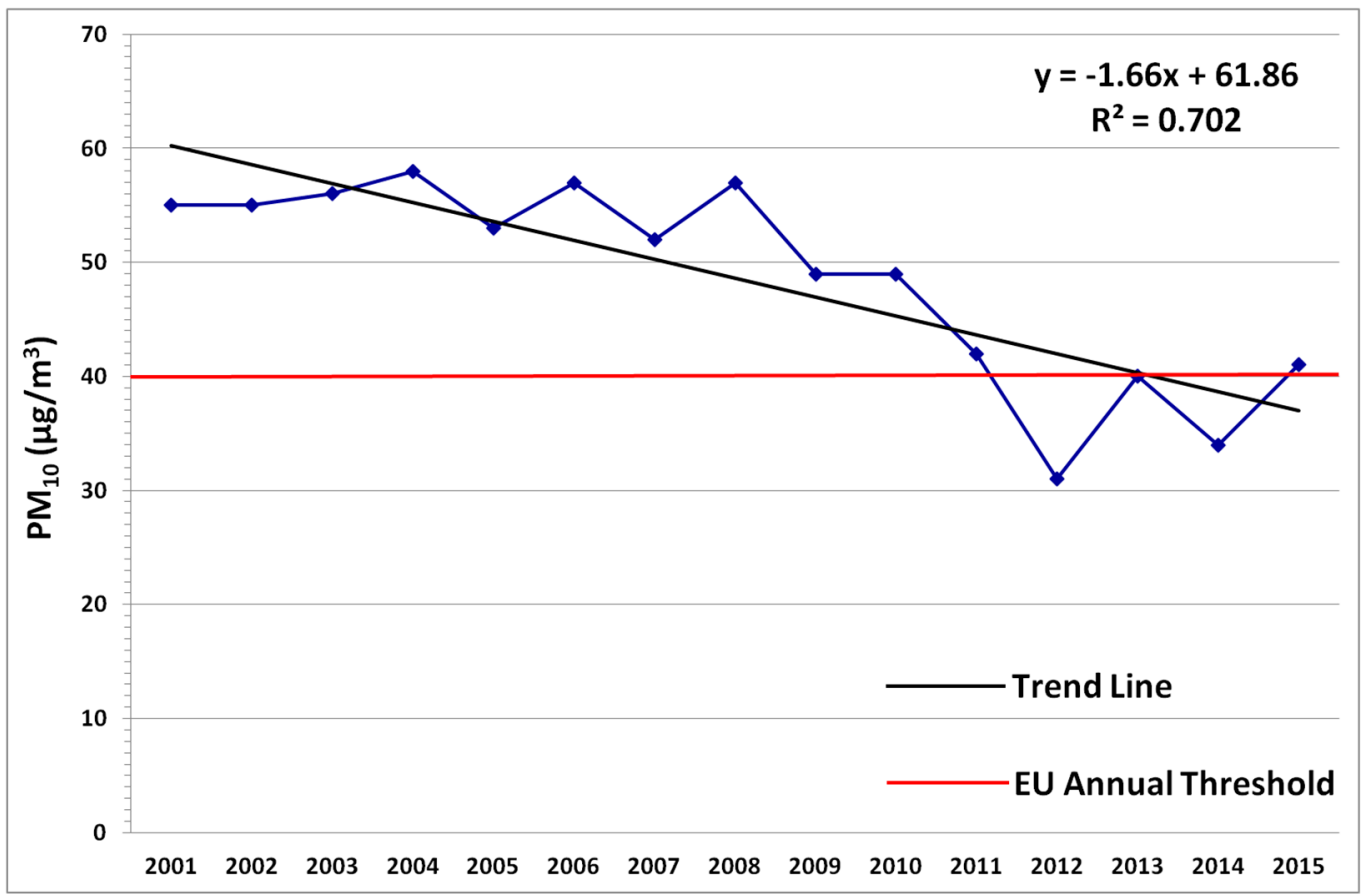

(a)

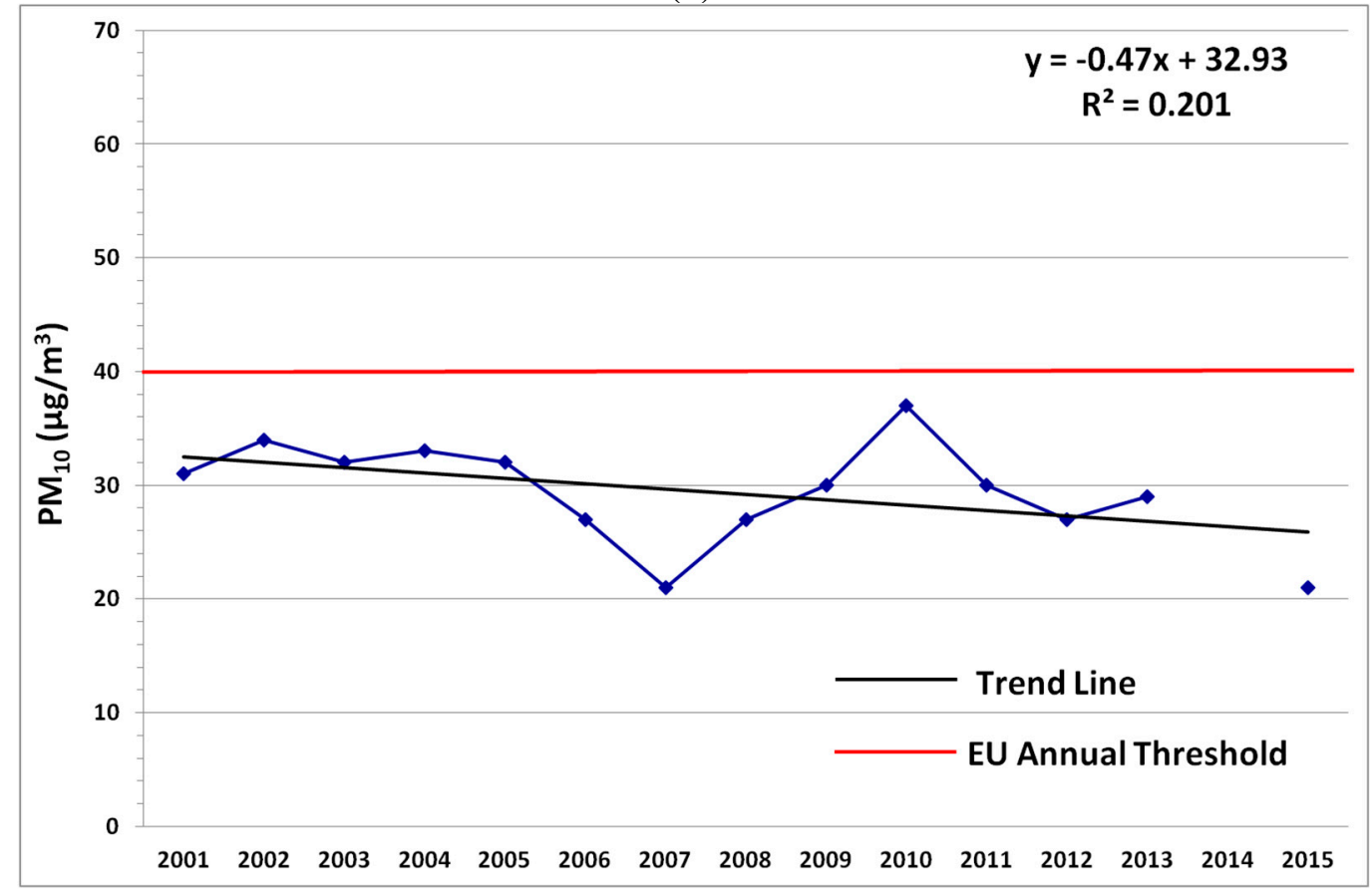

(b)

Figure 1: Mean annual $\mathrm{PM}_{10}$ concentrations at ARI (a) and THR (b) air pollution monitoring stations within the GAA. Period 2001-2015

By looking at Figure 1, we can see that for the city center ARI, the concentration of PM10 for the years 2001-2011 has been above the European Union (EU) Directive Threshold [20] of $40 \mu \mathrm{g} / \mathrm{m}^{3}$. However, for years 2011 to 2015 , improvements have been made and the concentration of $\mathrm{PM}_{10}$ is slightly below the EU directive threshold limit. It can also be estimated that the concentration of PM10 in ARI region has been decreasing from the year 2001 to 2015 by looking at the trend line of the graph which states that every year the concentration of $\mathrm{PM}_{10}$ in ARI has been decreasing at the rate of $-1.66 \mu \mathrm{g} / \mathrm{m}^{3}$ per year. For THR, the concentration for the year 2014 is not given due to lack of data. By looking at Figure $1 b$, we can see that the concentration of $\mathrm{PM}_{10}$ for the years 2001-2013 in THR has been below the EU Directive Threshold of $40 \mu \mathrm{g} / \mathrm{m}^{3}$. It can also be seen that the 
concentration of $\mathrm{PM}_{10}$ in THR region has been slightly decreasing from the year 2001 to 2015 by looking at the trend line of the graph which states that every year the concentration of $\mathrm{PM}_{10}$ has been decreasing at the rate of $-0.47 \mu \mathrm{g} / \mathrm{m}^{3}$ per year. By looking at both the graphs, we can see that there is huge difference in $\mathrm{PM}_{10}$ concentrations between the city center (ARI) and the suburban areas (THR) with the city center presenting high concentrations in comparison with the suburban areas (almost double). This might be due to traffic and also because of the fact that the city center is the most populated area within the GAA.

Figure 2 presents the mean monthly $\mathrm{PM}_{10}$ concentrations for both ARI and THR air pollution monitoring stations during the examined period 2001-2015.

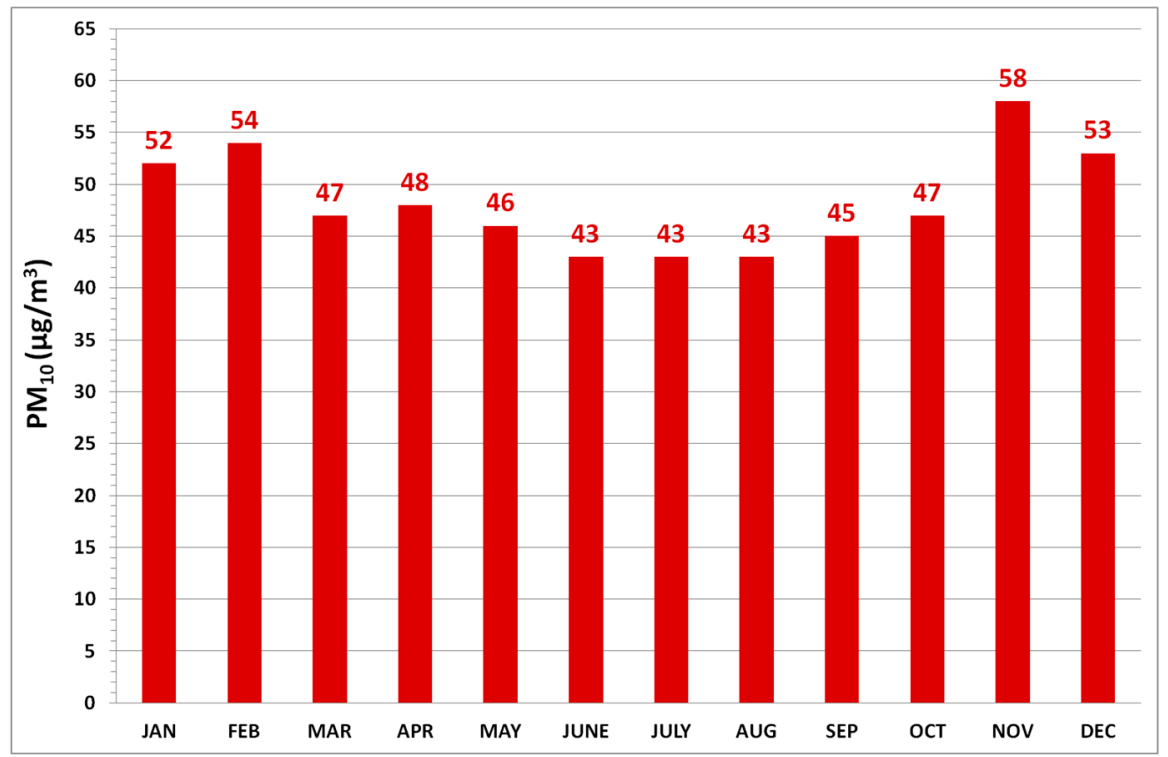

(a)

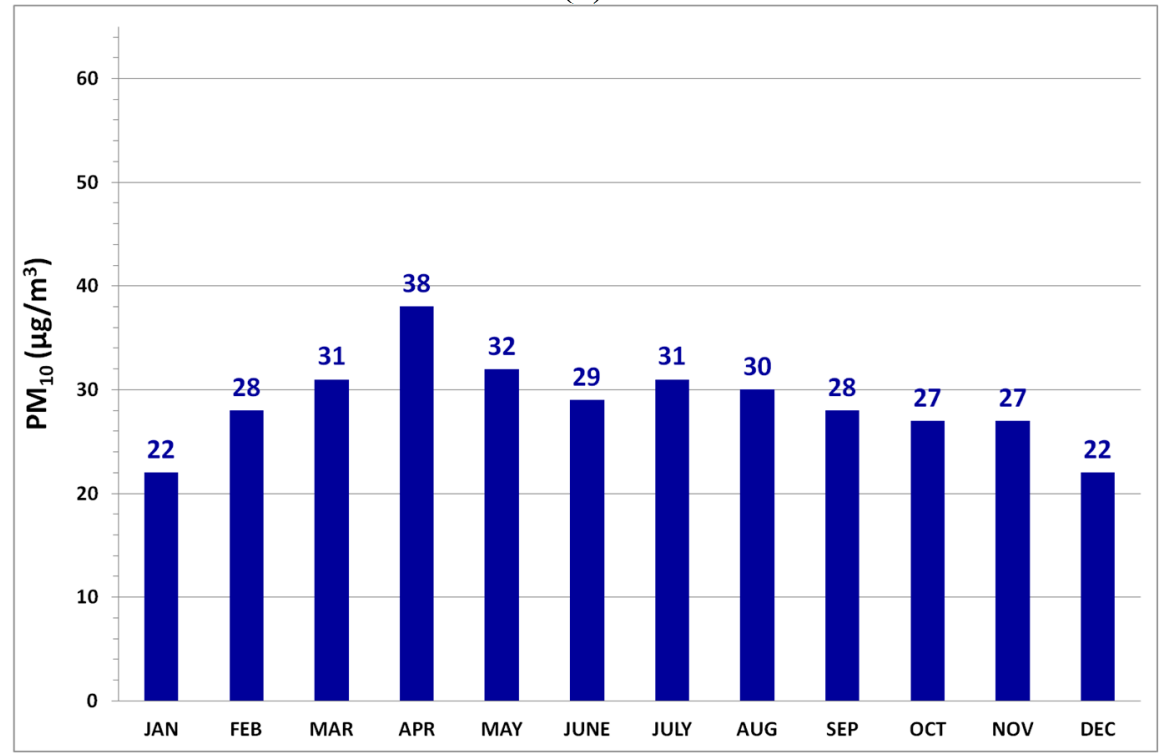

(b)

Figure 2: Mean monthly PM10 concentrations at ARI (a) and THR (b) air pollution monitoring stations within the GAA. Period 2001-2015.

By looking at Figure 2a, we can see that during the cold period of the year (October-April) the mean monthly concentrations of $\mathrm{PM}_{10}$ in ARI are higher than during the hot period of the year (May-September). This perhaps reinforces the view that traffic and burning oil or 
coal in heating systems are the major contributors of $\mathrm{PM}_{10}$ in the urban environment. Also, we can see that during the months June, July and August, the concentration of PM10 in ARI has almost been the same and the lowest of the year $\left(43 \mu \mathrm{g} / \mathrm{m}^{3}\right)$. This is probably due to the fact that during these three summer months, the most of GAA inhabitants are away from Athens city for summer vacations. For THR station (Figure $2 b$ ) we can see that during the spring period (March-May), the concentration of $\mathrm{PM}_{10}$ is the highest compared with the other seasons. The reason for this might be that THR is a suburban area with low population density and a huge number of plantations. As a result, there is higher concentration of $\mathrm{PM}_{10}$ there during the spring due to natural resources (e.g. pollen, dust, etc).

Figure 3 shows the intra-weekly variation of $\mathrm{PM}_{10}$ for both ARI (a) and THR (b) during the cold period of the year.

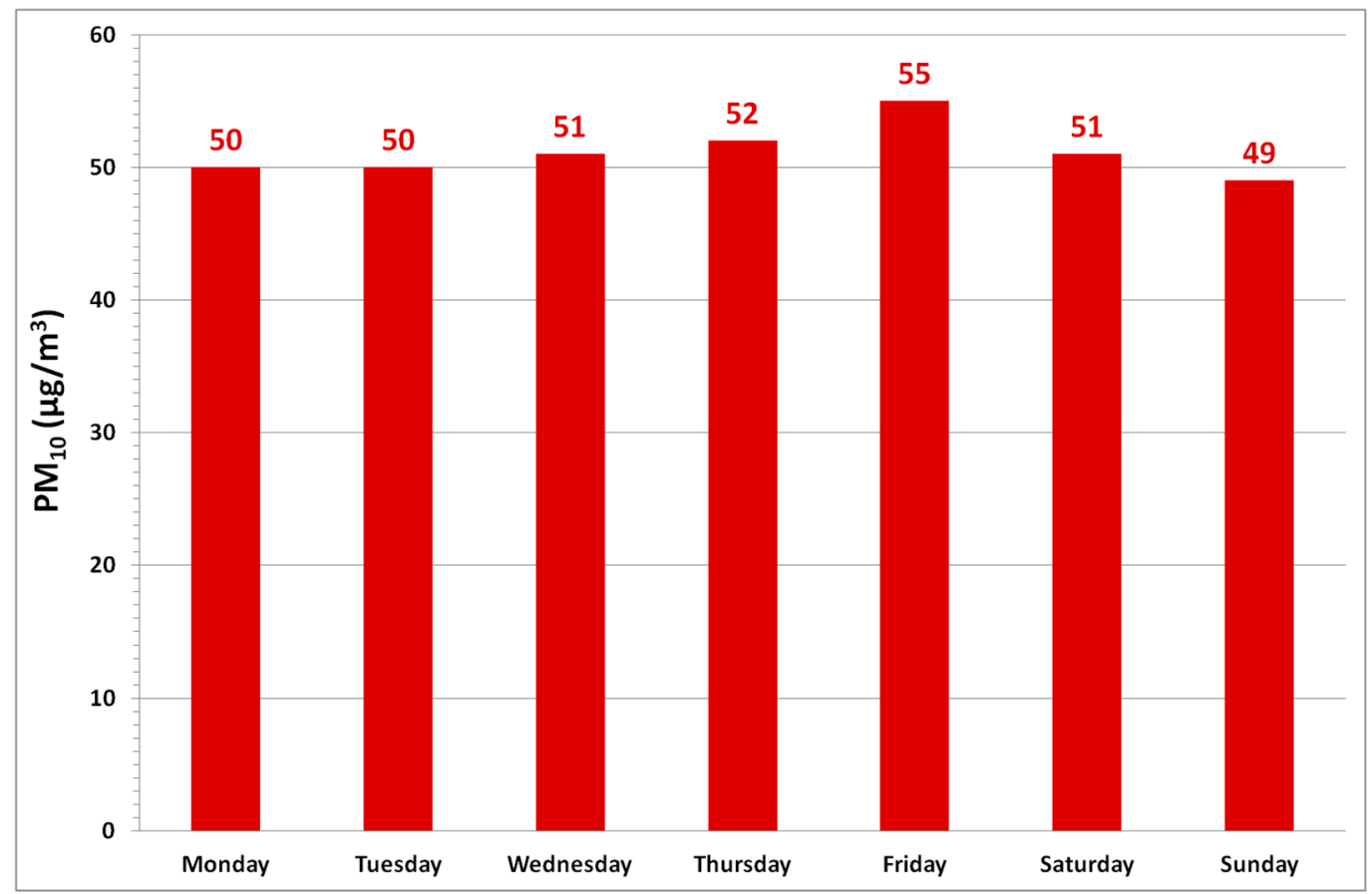

(a)

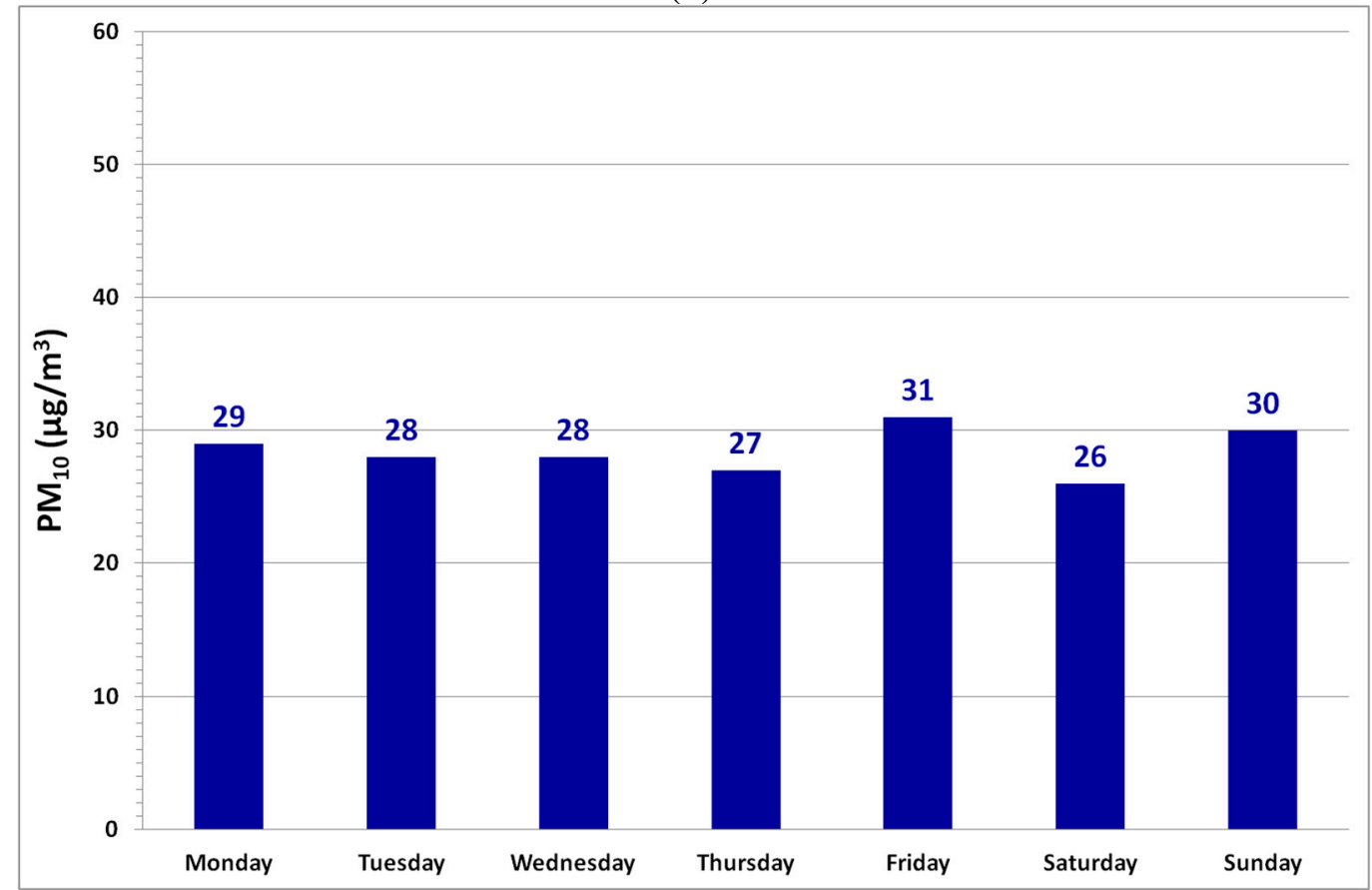


(b)

Figure 3: Intra-weekly variation of PM $\mathrm{PM}_{10}$ concentrations at ARI (a) and THR (b) air pollution monitoring stations within the GAA during the cold period of the year. Period 2001-2015

By looking at Figure 3a, we can see that on Friday, the concentration of $\mathrm{PM}_{10}$ in ARI is the highest while on Sunday it is the lowest. The reason for higher concentration of $\mathrm{PM}_{10}$ on Fridays in the city center is that Friday is the last working day of the week and so after work, people prefer to go for a night out or go meet their friends or make the last purchases of the week. As a result, the number of vehicles on the roads increases. The vehicles release harmful substances in the air including $\mathrm{PM}_{10}$ because of which the concentration of $\mathrm{PM}_{10}$ in ARI (city center) on Fridays is higher than the rest of the days. On Sunday, the concentration of $\mathrm{PM}_{10}$ is the lowest because usually on Sundays people prefer to stay in their homes as it is a holiday and most of the shops and supermarkets are closed. As a result, there are less people on the streets and hence less traffic because of which the concentration of $\mathrm{PM}_{10}$ is lowest during Sundays. For THR station (Figure 3b) we can see that on Friday, the concentration of $\mathrm{PM}_{10}$ is also the highest while on Saturday it's the lowest. The reason for higher concentration on Friday is probably the same as ARI. Finally, comparing the intra-weekly variation of $\mathrm{PM}_{10}$ at ARI and THR it is evident that in the city center for all the days of the week, $\mathrm{PM}_{10}$ concentrations are much higher than the corresponding at the suburban area of THR (almost double).

The same analysis for intra-weekly $\mathrm{PM}_{10}$ variation was also done for the warm period of the year. Figure 4 shows the intra-weekly variation of $\mathrm{PM}_{10}$ for both ARI (a) and THR (b) during the warm period of the year.

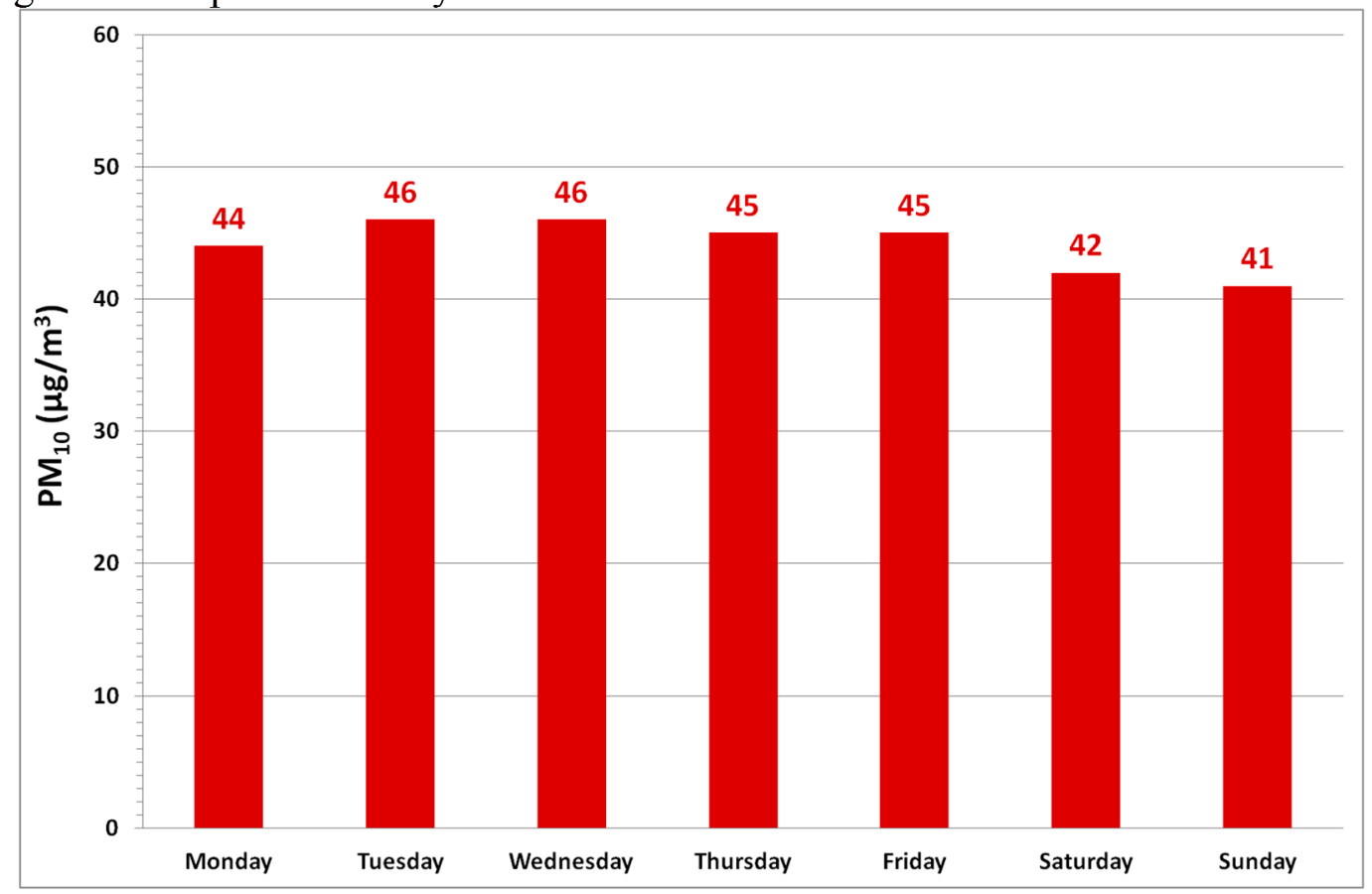

(a) 


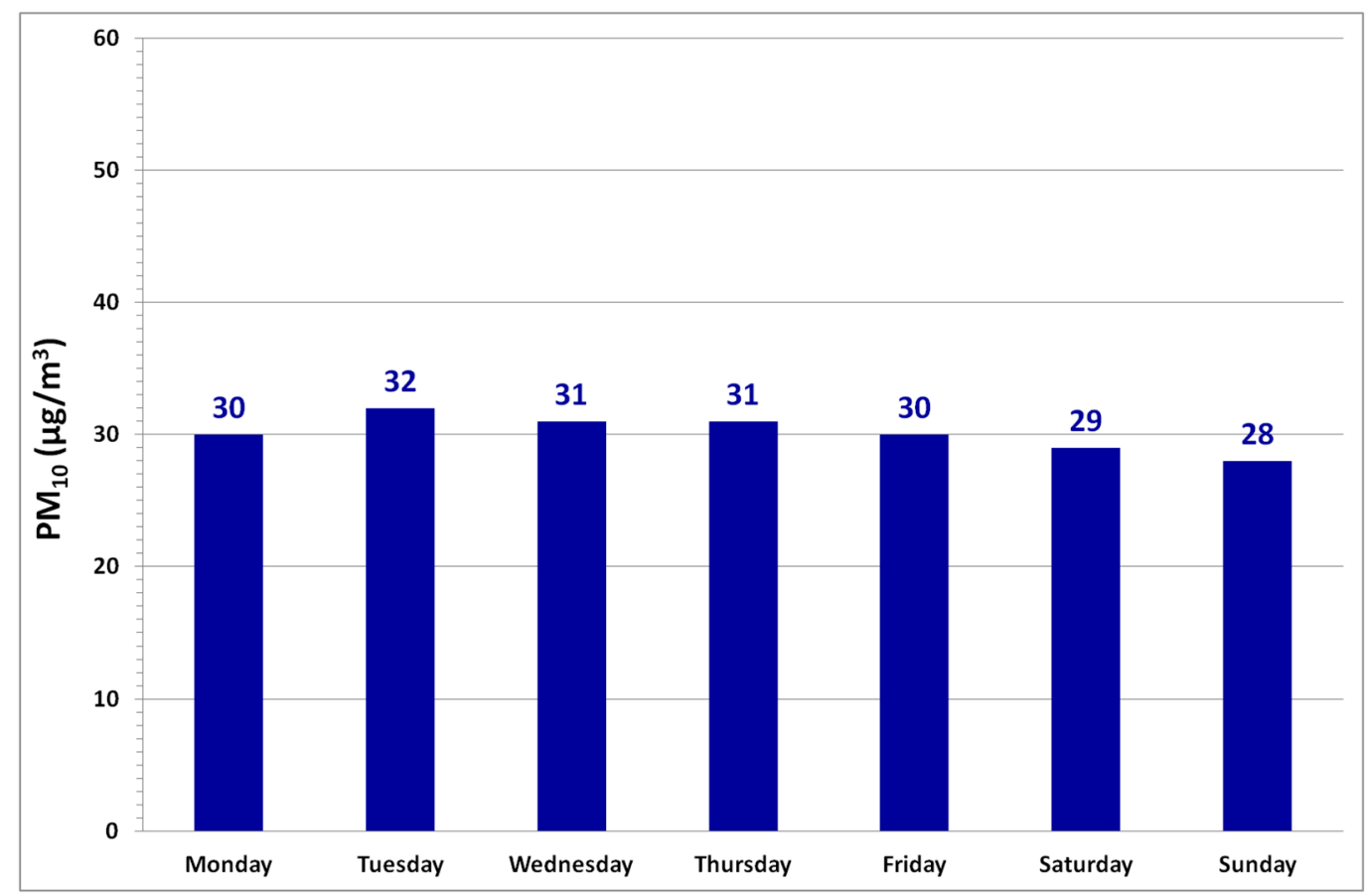

(b)

Figure 4: Intra-weekly variation of PM10 concentrations at ARI (a) and THR (b) air pollution monitoring stations within the GAA during the warm period of the year. Period 2001-2015

Figure $4 \mathrm{a}$ shows the weekly concentration of $\mathrm{PM}_{10}$ in ARI region during the warm period of the years 2001-2015. By looking at the graph, we can see that during the working days (Monday-Friday), the concentration of $\mathrm{PM}_{10}$ in ARI is higher than during the weekend (Saturday and Sunday). This is because on working days, people go for work using their cars, buses, etc. As cars release harmful pollutants in the air including $\mathrm{PM}_{10}$, the concentration of $\mathrm{PM}_{10}$ is higher during those days. In the weekends, people prefer to stay in their homes and so there are fewer vehicles on the streets and hence less PM10 particles are released in the air. THR (Figure 4b) follows the same trend as that of ARI. During the working days, there is higher $\mathrm{PM}_{10}$ concentration while during the weekends, there is less $\mathrm{PM}_{10}$ concentration. The reason might be the same as ARI as on working days there is usually more traffic than during the weekends. On Sundays, $\mathrm{PM}_{10}$ concentration is the lowest as it a holiday and most of the shops and supermarkets are closed because of which people prefer to stay in their homes. Finally, comparing the intra-weekly variation of $\mathrm{PM}_{10}$ at ARI and THR during the warm period of the year, it is evident that in the city center for all the days of the week, $\mathrm{PM}_{10}$ concentrations are much higher than the corresponding at the suburban area of THR (almost double). Also, during the warm period of the year, $\mathrm{PM}_{10}$ concentrations are lower in ARI than during the cold period of the year but in suburban area of THR, the case seems to be totally different. During the warm period of the year, $\mathrm{PM}_{10}$ concentrations are higher than the corresponding during the cold period of the year. This might be due to the presence of natural PM10 sources at THR station (dry weather, dry ground and dust).

According to the EU Directive 2008/50/EC [20], a daily threshold of $\mathrm{PM}_{10}$ concentration was established. So, if the mean daily concentration of $\mathrm{PM}_{10}$ is equal to or higher than $50 \mu \mathrm{g} / \mathrm{m}^{3}$ then that specific day is considered as an exceedance day. Also, the highest annual number of exceedance days is up to 35 days per year [20], which means $9.6 \%$ of the days of a calendar year. Taking into account the aforementioned daily threshold, for each one of the 
examined year (2001-2015), the annual number of exceedance days was calculated for both ARI and THR air pollution monitoring stations.

Figure 5 depicts the annual percentage (\%) of exceedance days during the examined period 2001-2015 for both ARI (a) and THR (b) air pollution monitoring stations within the GAA.

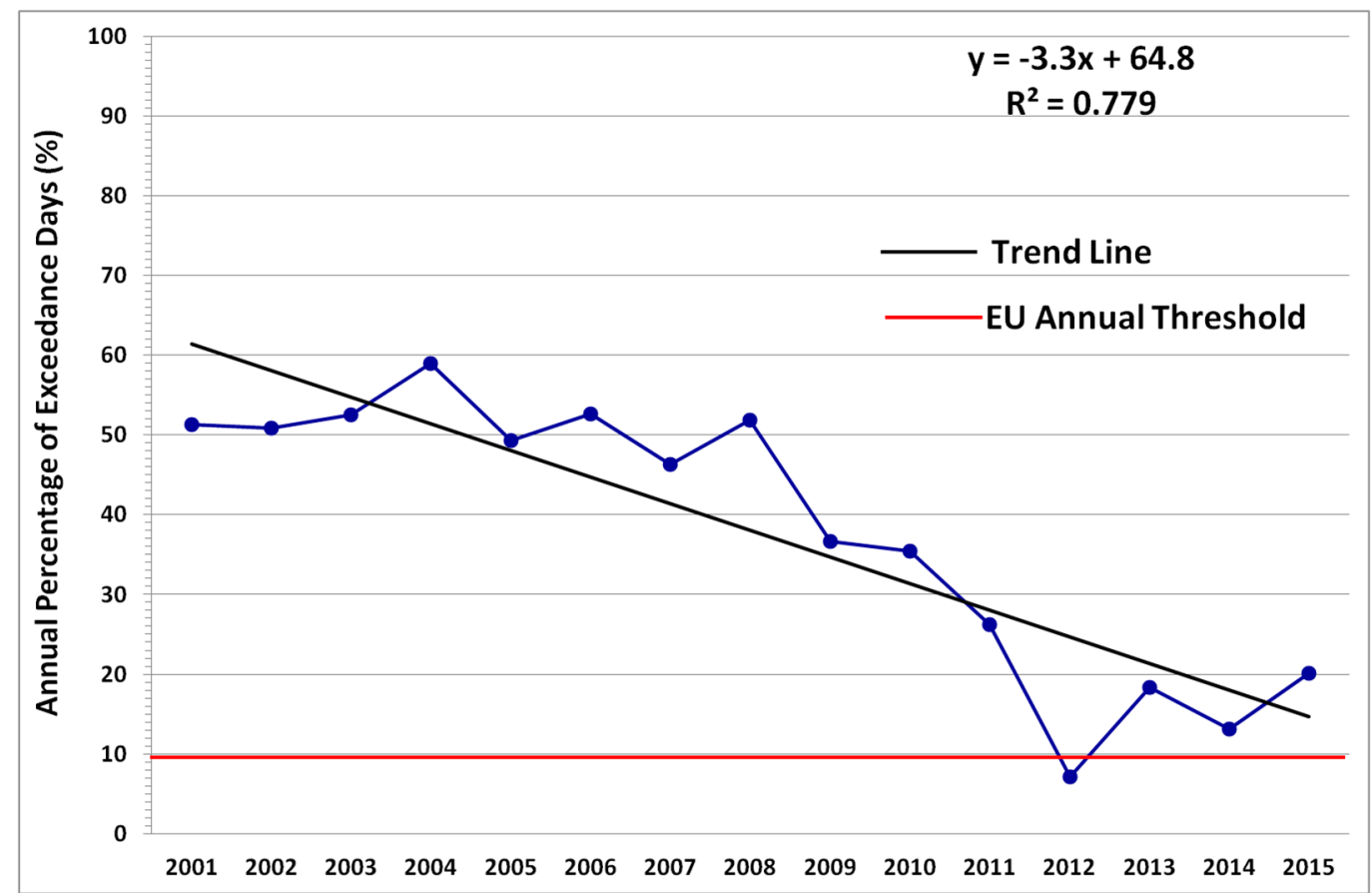

(a)

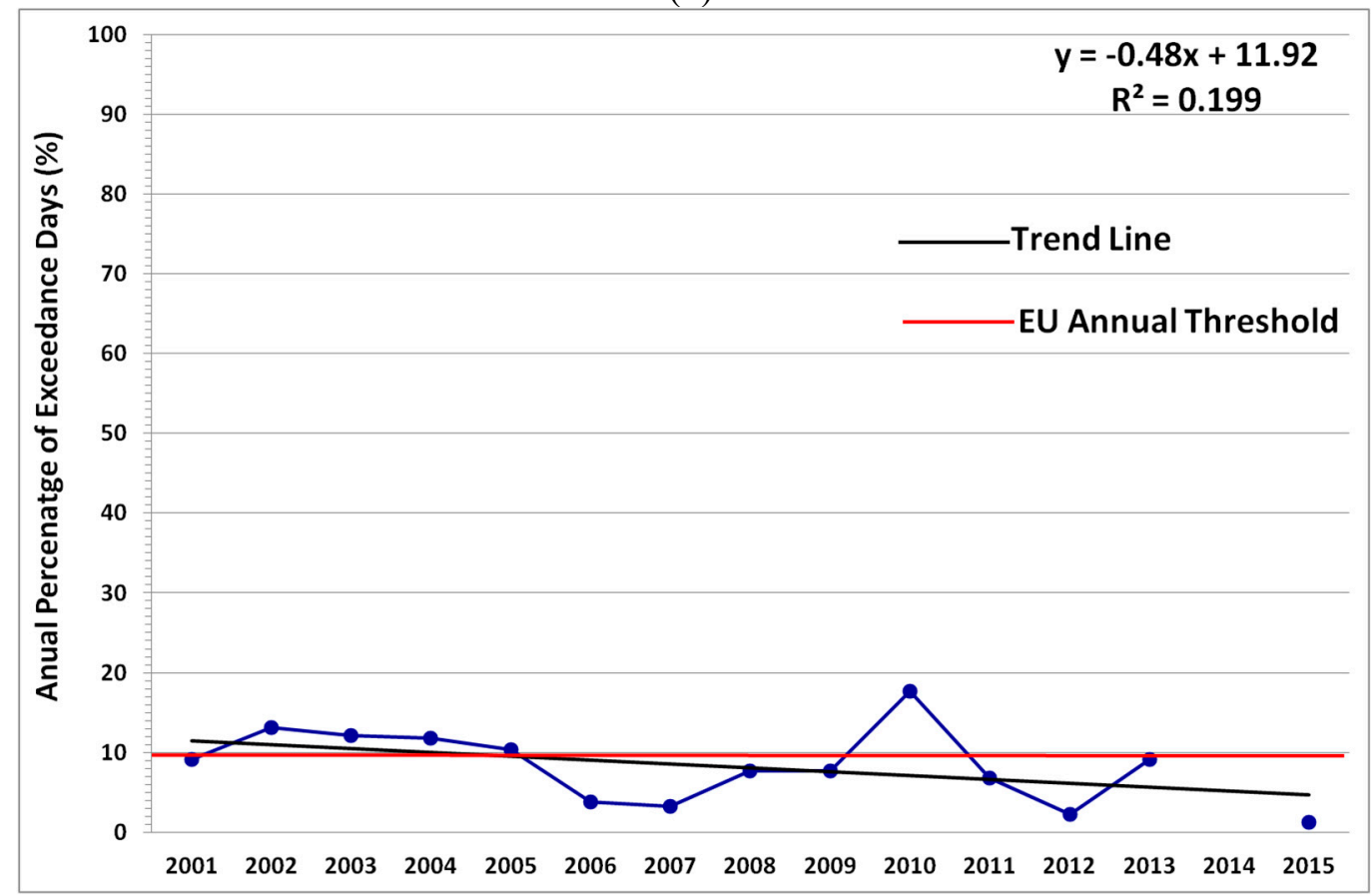

(b)

Figure 5: Percentage (\%) of annual exceedance days at ARI (a) and THR (b) air pollution monitoring stations within the GAA. Period 2001-2015

By looking at Figure 5a, we can see that from 2001 till 2015, the annual percentage (\%) of exceedance days is higher than the EU threshold limit of 9.6\%. However, during the examined period 2001-2015, the percentage has been decreasing sharply and by looking at the trend line we can see that it is decreasing at the rate of $-3.3 \%$ per year. The reason for 
such a huge decrease is that from 2002 onwards, new metro lines were introduced because of which people started to travel via the metros instead of using their personal cars. This with the combination of other actions and measures that have been taken by the government, greatly reduced the traffic on the streets, hence contributing to a decrease in the concentration of $\mathrm{PM}_{10}$ released in the air. For THR station, during the whole examined period 2001-2015, the annual percentage (\%) of exceedance days is around the EU threshold limit of $9.6 \%$ (except for the year 2010). By the trend line, we can see that the annual percentage of exceedance days in THR is decreasing at the rate of $-0.48 \%$ per year. The decrease is small because a steady state is presented at THR and so there is no major problem regarding the concentration of $\mathrm{PM}_{10}$ as THR is a suburban area.

Figure 6 depicts the time series of $\mathrm{PM}_{10}$ mean daily concentrations during 2001-2015 for ARI (a) and THR (b). It is evident that in the urban environment of Athens city center (Figure 6a) and taking into consideration the EU Directive for clean air, most of the days during the year are exceedance days $\left(\left[\mathrm{PM}_{10}\right] \geq 50 \mu \mathrm{g} / \mathrm{m}^{3}\right)$. In case of the suburban area of THR (Figure 6b), it seems that PM10 presents a lower concentration with a small number of exceedance days during the year. In both cases (ARI and THR), the extreme PM10 concentrations have been related, in most cases, with the Sahara dust event [23-24] (transportation of African dust).

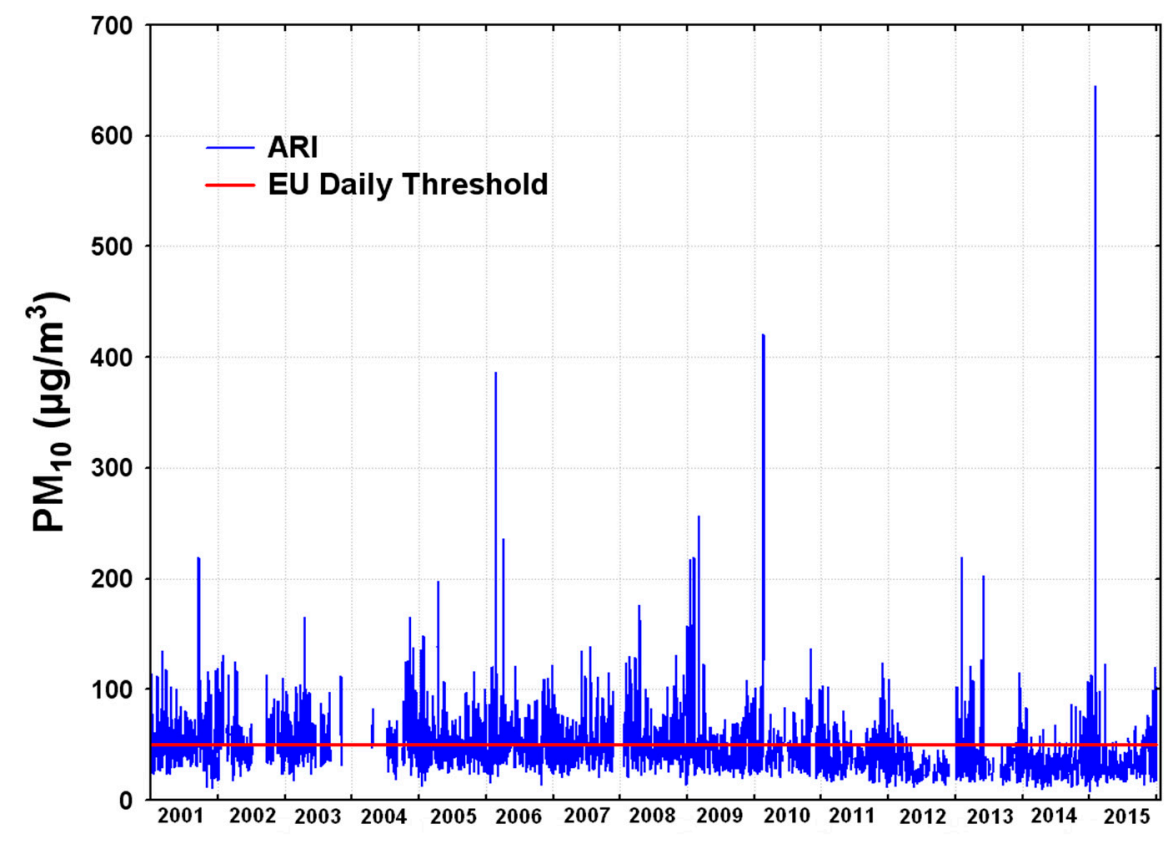

(a) 


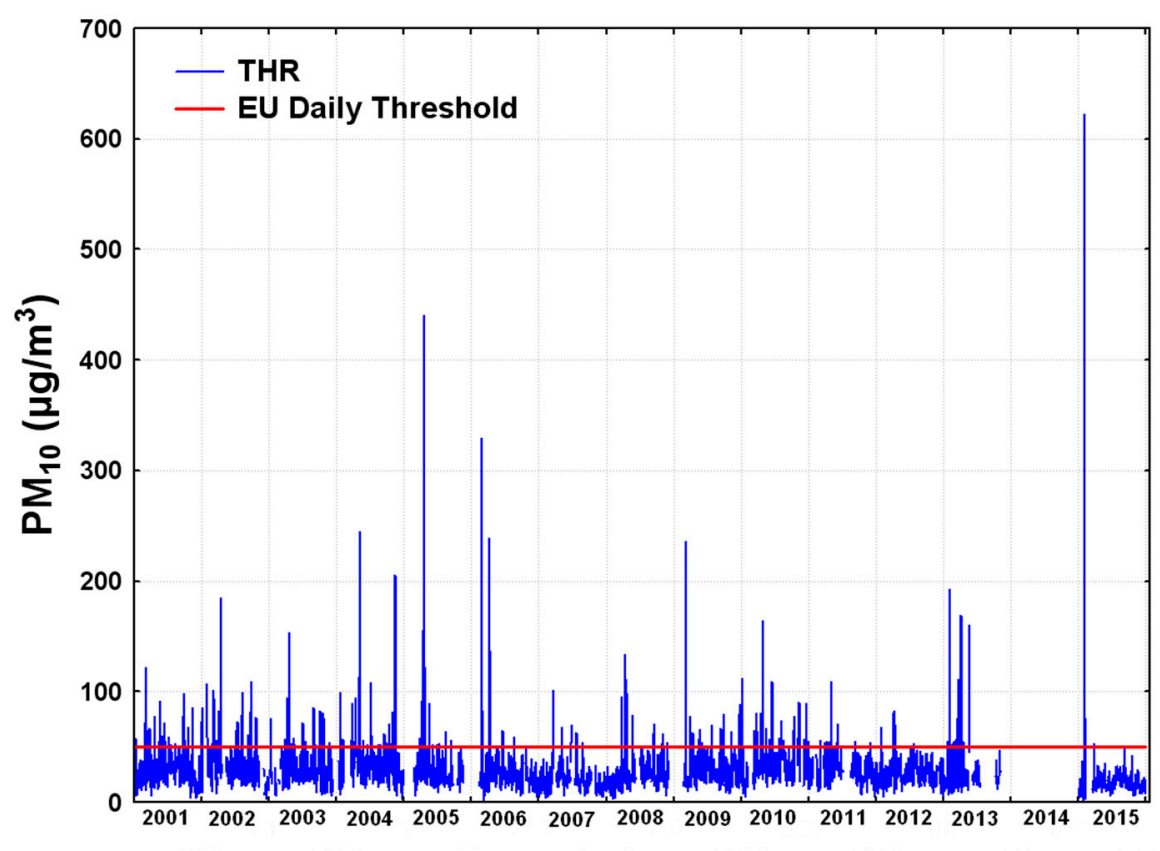

(b)

Figure 6: Diurnal variation of PM10 concentrations for ARI (a) and THR (b). Period 20012015

Figure 7 shows the frequency distribution of the mean daily $\mathrm{PM}_{10}$ concentrations in both examined monitoring sites ARI and THR during the period 2001-2015.

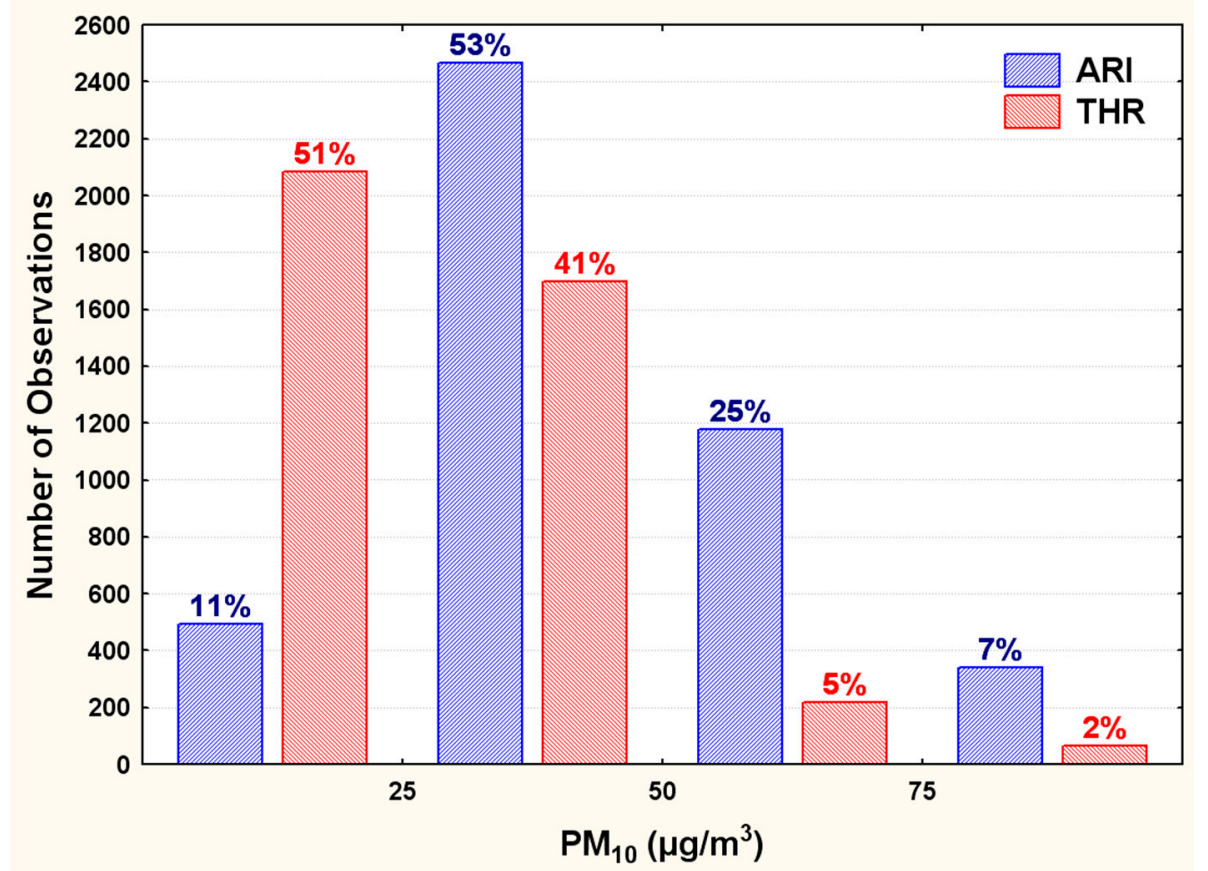

Figure 7: Frequency distribution of the mean daily $\mathrm{PM}_{10}$ concentrations in both examined monitoring sites ARI and THR. Period 2001-2015

According to Figure 7, it is evident that in the city center the air quality is poorer than the air quality in the suburban area of THR. More specifically, at the city center (ARI) $53 \%$ of the days per year (almost half year) presents a middle level of $\mathrm{PM}_{10}$ concentrations that indicates a moderate air quality. Therefore, during half of the year, the inhabitants of the 
city center live under moderate $\mathrm{PM}_{10}$ concentrations. Furthermore, a percentage of $32 \%$ (every third day) are exceedances days with $\mathrm{PM}_{10}$ concentrations above the EU threshold value of $50 \mu \mathrm{g} / \mathrm{m}^{3}$ indicating a poor air quality. On the other hand, the suburban area of THR presents a percentage of $51 \%$ of the days per year (almost half of the year) with good air quality and only $7 \%$ of the days per year have $\mathrm{PM}_{10}$ concentrations above the EU threshold value of $50 \mu \mathrm{g} / \mathrm{m}^{3}$.

\section{Materials and Methods}

The city of Athens is located in an area of a complex topography within the Athens basin $\left(\sim 450 \mathrm{~km}^{2}\right)$. Mountains surround the city from the north, west and east sides with heights ranging from $400 \mathrm{~m}$ to $1500 \mathrm{~m}$. Openings between these mountains exist at the northeast and west of the basin, while the sea extends southwards (Saronikos Gulf). The Athens basin has a southwest to northeast major axis and is bisected by a cluster of small hills. In late summer, fall and winter, the prevailing winds in the Athens basin blow from North $(\mathrm{N})$ to Northeast (NE) while in the spring and early summer, they blow from South-Southwest (SSW) to Southwest (SW). The NE and SW directions coincide with the major geographical axis of the basin. During the prevalence of local circulation systems, such as sea/land breezes along the major NE-SW geographical axis of the basin, the ventilation of the basin is poor [21-22]. The geography of the area does not favor the dispersion of air pollutants. The main emissions are due to transport (vehicle emissions), industry, and domestic heating.

The aim of the specific work is to statistically treat $\mathrm{PM}_{10}$ concentrations and to investigate the temporal variation of $\mathrm{PM}_{10}$ concentrations at two different locations within the GAA during the time period 2001-2015. More specifically, mean daily $\mathrm{PM}_{10}$ concentrations from two different air pollution monitoring sites, Thrakomakedones (THR) and Aristotelous (ARI) have been used (Figure 8). ARI is located at Athens city center and is characterized as a city center traffic monitoring station. Furthermore, THR is located at the north side of GAA and is characterized as a suburban background monitoring station. The mean daily concentrations of $\mathrm{PM}_{10}$ used in this research have been recorded by the air pollution monitoring network of the Greek Ministry of Environment and Energy (GMEE). 


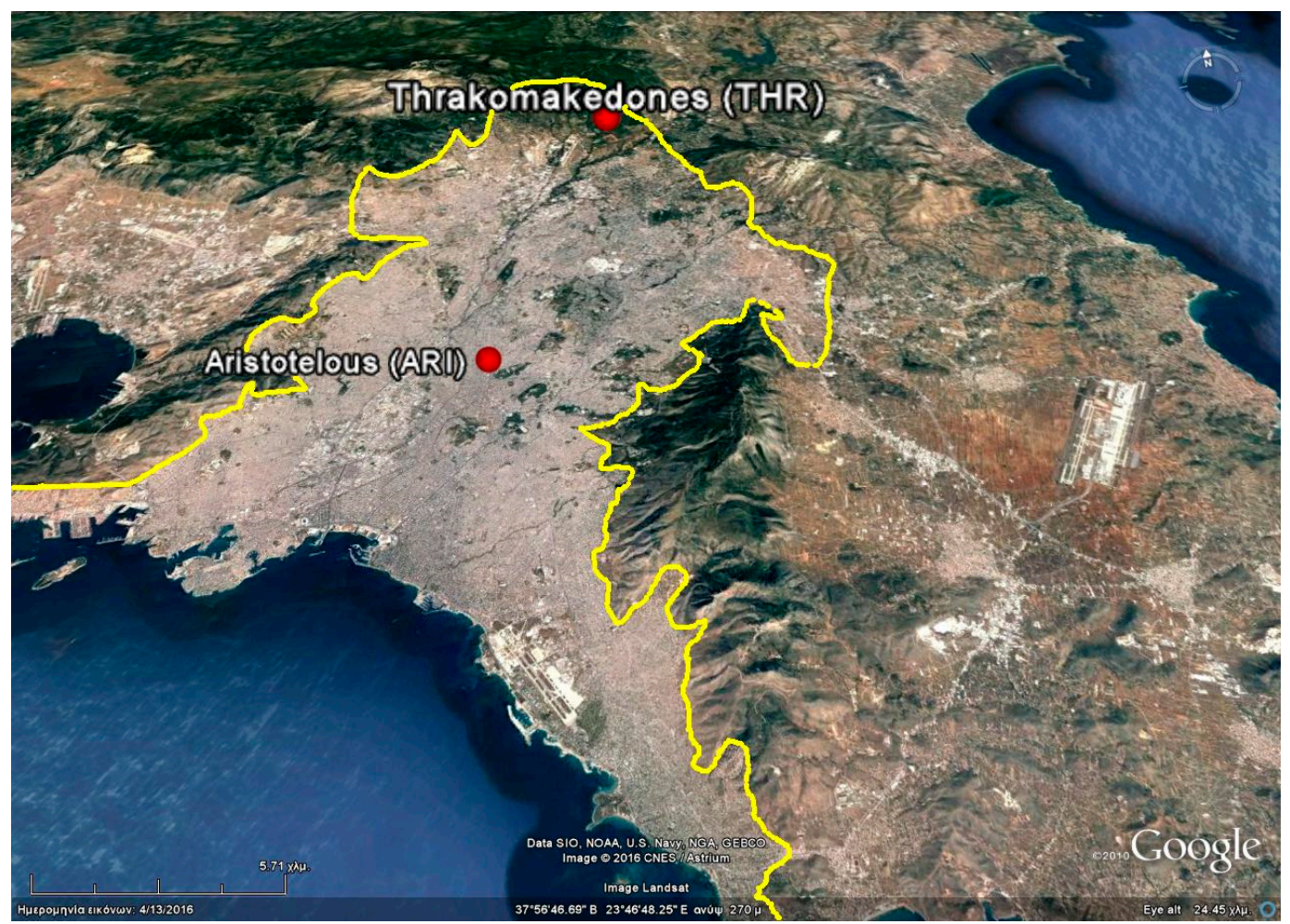

Figure 8: The map of the GAA with the two air pollution monitoring stations

Initially, for each station the mean annual, mean monthly and mean daily concentrations of $\mathrm{PM}_{10}$ were calculated. Then, a statistical treatment took place and graphs with annual variation of $\mathrm{PM}_{10}$ concentrations; monthly variation and inter-weekly variation were extracted combined by respective conclusions.

\section{Conclusions}

In this study mean daily $\mathrm{PM}_{10}$ concentrations within the greater urban Athens area during the time period 2001-2015 were analyzed. Results showed that there is a significant decreasing trend of the annual $\mathrm{PM}_{10}$ concentration for both the Athens city center and the suburban area of Thrakomakedones. A strong seasonality in Athens urban center was found with minima during warm period of the year and maxima during the cold period of the year. Totally opposite seasonality at Thrakomakedones suburban area appeared. Also, for both the city center and the suburban area, during the weekends, a minimum mean daily concentration of $\mathrm{PM}_{10}$ was found. Finally, there was a huge number of exceedances days, according to the EU directive for clean air ([PM10] $\geq 50 \mu \mathrm{g} / \mathrm{m} 3)$ per year, in the city center with a significant decreasing trend during the examined period.

In conclusion, we can say that $\mathrm{PM}_{10}$ is a major air pollutant for the GAA but shows a decreasing trend during the last decade, demonstrating that the measures taken by the state are beginning to pay off (new metro lines, new highways across the GAA, new airport services away from the urban agglomeration of Athens city, dedicated bus lanes, etc).

\section{References}

1. Schwartz, J.; Slater, D.; Larson, T.; Pierson, W.E.; Koeng, J.Q. Respiratory health and PM10 pollution-a daily time series analysis. Am Rev Respir Dis, 1991, 147, pp. 826-831.

2. Dockery, D.W.; Pope, C.A.; Xu, X.; Spengler, J.D.; Ware, J.H.; Fay, M.E.; Ferris, B.G.; Spizer, F.E. An association between air pollution and mortality in six US cities. New Engl J Med, 1993, 329, pp. 1735-1759. 
3. Seaton, A.; MacNee, W.; Donaldson, K.; Godden, D. Particulate air pollution and acute health effects. Lancet, 1995, 345, pp. 176-178.

4. Pope III, C.A. Epidemiology of fine particulate air pollution and human health: biological mechanisms and who's at risk? Environ Health Persp, 2000, 108, pp. 713-723.

5. Grigoropoulos, K.N.; Natos, P.T.; Ferentinos, G.; Gialouris, A.; Vasiliou, T.; Mavroidakos, J.; Avgeri, D.; Kalabokis, V.; Saratsiotis, D. Spatial distribution of PM1 and Sinus Arrhythmias in Athens, Greece. Fresen Envrion Bull, 2008, 17(9b), pp. 1426-1431.

6. Harrison, R.M. and Yin, J. Particulate matter in the atmosphere: which particle properties are important for its effects on health? Sci Total Environ, 2000, 249, pp. 85-101.

7. Nastos, P.T. and Matzarakis, A. Weather impacts on respiratory infections in Athens, Greece. Int J Biometeorol, 2006, 50(6), pp. 358-369.

8. Bartzokas, A.; Kassomenos, P.; Petrakis, M.; Celessides, C. The effect of meteorological and pollution parameters on the frequency of hospital admissions for cardiovascular and respiratory problems in Athens. Indoor Built Environ, 2004, 13, pp. 271-275.

9. Pope III, C.A.; Burnett, R.T.; Thurston, G.D.; Thun, M.J.; Calle, E.E.; Krewski, D. and Godleski, J.J. Cardiovascular mortality and long-term exposure to particulate air pollution. Epidemiological evidence of general pathophysiological pathways of disease. Circulation, 2004, 109, pp. 71-77.

10. Schwartz, J.; Slater, D.; Larson, T.V.; Pierson, W.E.; Koenig, J.Q. Particulate air pollution and hospital emergency room visits for asthma in Seattle. Am Rev Respir Dis, 1993, 147, pp. 826-831.

11. Dockery, D.W. and Pope III, C.A. Acute respiratory effects of particulate air pollution. Annu Rev Publ Health, 1994, 15, pp. 107-132.

12. Galán, I.; Tobías, A.; Banegas, J.R. Short-term effects of air pollution on daily asthma emergency room admissions. Eur Respir J, 2003, 22, pp. 802-808.

13. Boldo, E.; Medina, S.; LeTertre, A.; Hurley, F.; Mückem H.G.; Ballesterm, F.; Aguilera, I.; Eilstein, D. On behalf of the Apheis group, 2006: Apheis: Health impact assessment on long-term exposure to $\mathrm{PM}_{2.5}$ in 23 European cities. Eur J Epidemiol, 2006, 21, pp. 449-458.

14. Li, N. and Nel, A.E. Role of the Nrf2-Mediated signalling pathway as a negative regulator of inflammation: Implications for the impact of particulate pollutants on asthma. Antioxid Redox Sign, 2006, 8, pp. 88-98.

15. Progiou, A.G.; Ziomas, I.C. Predicting annual average particulate concentration in urban areas. Sci Total Environ, 2015, 532, pp. 353-359.

16. Paraskevopoulou, D.; Liakakou, E.; Gerasopoulos, E.; Mihalopoulos, N. Sources of atmospheric aerosol from long-term measurements (5 years) of chemical composition in Athens, Greece. Sci Total Environ, 2015, 527-528, pp. 165-178.

17. Benas, N.; Beloconi, A.; Chrysoulakis, N. Estimation of urban PM10 concentration, based on MODIS and MERIS/AATSR synergistic observations. Atmos Environ, 2013, 79, pp. 448-454.

18. Remoundaki, E.; Bourliva, A.; P. Kokkalis, P.; Mamouri, R.E.; Papayannis, A.; Grigoratos, T.; Samara, C.; Tsezos, M. PM10 composition during an intense Saharan dust transport event over Athens (Greece). Sci Total Environ, 2011, 409, pp. 4361-4372.

19. Grivas, G.; Chaloulakou, A.; Kassomenos, P. An overview of the PM10 pollution problem, in the Metropolitan Area of Athens, Greece. Assessment of controlling factors and potential impact of long range transport. Sci Total Environ, 2008, 389, pp. 165-177.

20. Directive 2008/50/EC of the European Parliament and of the Council (2008) On ambient air quality and cleaner air for Europe. Official Journal of the European Union, L $152 / 1-43$

21. Nastos, P.T.; Philandras, C.M.; Paliatsos, A.G. (2002). Fourier analysis of the mean monthly NOx concentrations in the Athens basin. Global Nest J, 2002, 4(2-3), pp. 145-152. 
22. Larissi, I.K; Koukouletsos, K.V.; Moustris, K.P.; Antoniou, A.; Paliatsos, A.G. PM10 concentrations levels in the greater Athens area, Greece. Fresen Envrion Bull, 2010, 19(2), pp. 226-231.

23. Paschalidou, A.K.; Kassomenos, P.; Karanikola, P. Disaggregating the contribution of local dispersion and long-range transport to the high PM10 values measured in a Mediterranean urban environment. Sci Total Environ, 2015, 527-528, pp. 119-125.

24. Aleksandropoulou, V.; Lazaridis, M. Identification of the Influence of African Dust on PM10 Concentrations at the Athens Air Quality Monitoring Network during the Period 2001-2010. Aerosol Air Qual Res, 2013, 13, pp. 1492-1503.

(C) 2016 by the authors; licensee Preprints, Basel, Switzerland. This article is an open access article distributed under the terms and conditions of the Creative Commons by Attribution (CC-BY) license (http://creativecommons.org/licenses/by/4.0/). 